\title{
Application of Bromocresol Green and Bromothymol Bluefor the Extractive Spectrophotometric Determination of Anti-hypertensive Drugs
}

\author{
Akram M. El-Didamony ${ }^{1}$, Sameh M. Hafeez ${ }^{2}$, Ahmed A. Saad ${ }^{1}$ \\ ${ }^{1}$ Chemistry Department, Faculty of Science, Zagazig University, Zagazig 44519, Egypt. \\ ${ }^{2}$ Ismailia Chemical Laboratory, Forensic Medicine Authority, Justice Ministry, Egypt.
}

\begin{tabular}{l} 
ARTICLE INFO \\
\hline Article history: \\
Received on: 10/04/2015 \\
Revised on: 02/05/2015 \\
Accepted on: 16/06/2015 \\
Available online: $27 / 07 / 2015$ \\
\hline Key words: \\
Antihypertensive drugs, \\
Extraction spectrophotometry, \\
BCG and BTB dyes; Ion-pair \\
complex, Pharmaceutical \\
formulations.
\end{tabular}

\section{INTRODUCTION}

Telmisartan (TEL, Fig. 1a) is a highly selective angiotensin II type 1 receptor antagonist, widely used in the treatment of hypertension and heart failure (Yusuf et al., 2008; Pitt and Konstam, 1998). It can selectively block the angiotensin type 1 receptor without affecting other receptor systems involved in cardiovascular regulation. Literature survey reveals several methods for determination of TEL individually in biological fluids and formulation like LC (Babu et al., 2012; Gupta et al., 2011; Rao et al., 2011; Jyothi and Nalluri, 2012), HPLC (Seelam et al., 2010; Zhang et al., 2009), voltammetry (Alarfaj, 2013), spectrophotometry and derivative spectrophotometry (Ilango and Kumar, 2012; Qin et al., 2009). Propranolol (PRO, Fig. 1b) is one of common $\beta$-blockers, which is widely used in clinical treatment of cardiovascular diseases such as angina, hypertension

* Corresponding Author

Akram M. El-Didamony, Chemistry Department, Faculty of Science,

Zagazig University, Zagazig, Egypt.Email:ak_eldidamony@yahoo.com arrhythmia and so on (Sweetman, 2002). Its structure is shown in Fig.1. Several methods for the analytical determination of PRO in pharmaceutical formulations have been reported in the literature, by spectrophotometry (El-Didamony, 2010; Basavaiah et al., 2004; Zahálka et al., 2013), spectrofluorometry (Rekhi et al., 1995) and HPLC (Šatínský et al., 2013; Salman et al., 2010; El-Sahart, 2003; Abdel-Hamid, 2000). Carvedilol (CRV, Fig. 1c) is a non-selective and $\beta$-adrenergic antagonist with no intrinsic sympatomimetic activity and is widely used to treat essential hypertension and angina pectoris (Anderson, 2002; Moffat et al., 2004).

Carvedilol is also indicated for the treatment of mild to severe chronic heart failure, Left ventricular dysfunction following myocardial infarction in clinically stable patients and hypertension. $\beta$-blockers affect the heart and blood circulation (Flanagan, 1998). Analytical methods such as HPLC (Belal et al., 2013; Machida et al., 2003; Zarghi et al., 2007), differential pulse voltammetry (Dogan and Ozkan, 2005) and spectrofuorimetry (Önal, 2011; Cardoso et al., 2007) have been used for the determination of CRV. 
Bisoprolol (BIS, Fig. 1d) is a second-generation selective beta-blocker without intrinsic sympathetic activity. It is effective in reducing blood pressure (Dubach et al., 2002). Several analytical methods have been studied for the determination of BIS in biological fluids.

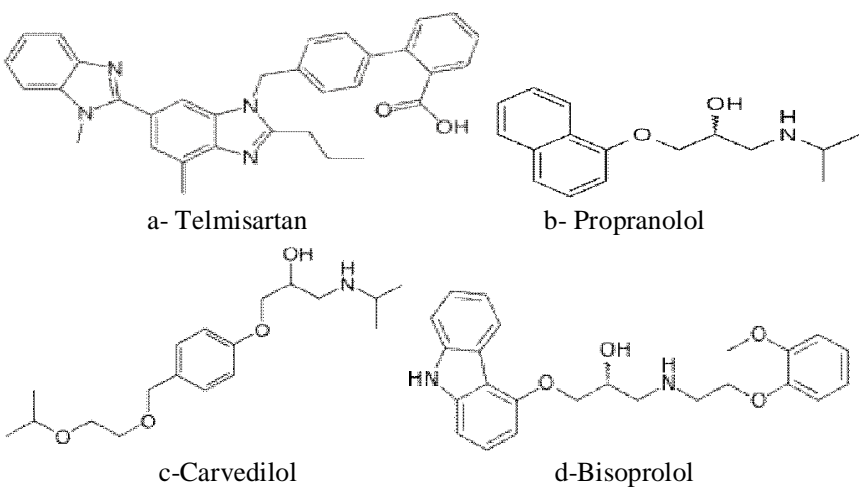

Fig. 1: Chemical structure of the studied drugs.

Among these methods, HPLC (Joshi et al., 2010; Tutunji et al., 2009; Shaikh et al., 2008; Patel et al., 2006), LC-MS-MS (Peste et al., 2010; Ding et al., 2007; Caudron et al., 2004) have been utilized for the determination of BIS. Some methods have also been reported for the determination of BIS in pharmaceutical preparations. These articles include voltammetry (Goyal et al., 2008) and spectrophotometry (Sahu and Patel, 2006; El-Didamony et al., 2012; El-Didamony and Shehatab, 2014).

Hypertension is a major cause of morbidity and mortality worldwide. Anti-hypertensive medication is effective in reducing blood pressure. Therefore, this paper proposes two simple and sensitive extractive spectrophotometric methods for the determination of four antihypertensive drugs. The methods are based on ion-pair complexes of drugs with dyestuffs such as bromocresol green (BCG) and bromothymol blue (BTB) and subsequent extraction into dichloromethane under reaction conditions used.

\section{MATERIALS AND METHODS}

\section{Apparatus}

All the absorbance spectral measurements were made using Shimadzu spectrophotometer model: 1800-240V, made in Japan, spectral bandwidth $2.0 \mathrm{~nm}$, with $10 \mathrm{~mm}$ matched quartz cells. The $\mathrm{pH}$ values of buffer solutions were measured using Jenway instrument $\mathrm{pH}$-meter (combined electrode).

\section{Reagents and Solutions}

All of the chemicals used were of analytical or pharmaceutical grade and used without further purification. Double distilled de-ionized water was used to prepare all solutions.

i. Pharmaceutical grade of TEL, PRO, CRV and BIS certified to be $99.85 \%$ pure was obtained as gift were kindly supplied from Egyptian International Pharmaceutical Industries Company (EIPICo), Egypt. Stock solutions of pure TEL, PRO, CAR and BIS were prepared separately by dissolving accurately weighed 20 $\mathrm{mg}$ of each drug in a $100 \mathrm{ml}$ calibrated flask. Working solutions of lower concentrations were freshly prepared by appropriate dilution with water.

ii. A $1.0 \times 10^{-3} \mathrm{M}$ of bromothymolol blue and bromcresol green (Aldrich Co., Ltd., Gillingham-Dorst, Germany), were prepared by dissolving accurate weight from each dye in $2 \mathrm{ml}$ methanol then, add $20 \mathrm{ml}$ distilled water and diluted to $100 \mathrm{ml}$ in a calibrated flask with distilled water to the mark.

iii. Commercial dosage forms of TEL (Micardis $40 \mathrm{mg}$, Boehringer Ingelheim Co., Germany), PRO (Inderal 10 $\mathrm{mg}$, EIPICo $10^{\text {th }}$ of Ramadan, Egypt), CRV (Carvid 7.5mg Multi-apex, Badr-city, Cairo) and BIS (10 mg/tablet Concor, product of Amoun Pharmaceutical Co., El-Obour city, Egypt) .

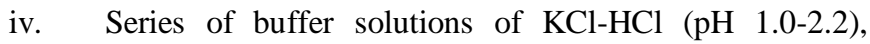
$\mathrm{NaOAc}-\mathrm{HCl}$ (1.99-4.92) and $\mathrm{NaOAc}-\mathrm{AcOH}(3.4-5.6) \mathrm{pH}$ were prepared by standard methods.

\section{General Recommended Procedures Ion-pair Method Using BCG}

Into a series of separated funnels, accurately measured aliquots of TEL, PRO, CRV and BIS in the concentration range shown in (Table 1) were pitted out. A volume of $2.0 \mathrm{ml}$ of $1.0 \times 10^{-}$ ${ }^{3} \mathrm{M}$ BCG was added. Then, $2.0 \mathrm{ml}$ of the buffer solution of $\mathrm{pH}=2$ for TEL or CRV and $\mathrm{pH}=4$ for PRO or BIS were added in each case and the volume was completed to $10 \mathrm{ml}$ with distilled water. The contents were extracted with $10 \mathrm{ml}$ dichloromethane and the organic layer was dried over anhydrous sodium sulfate. The absorbance of the yellow colored complexes was measured at 402 against a reagent blank prepared similarly. Calibration plots were drawn to calculate the amount of drugs in unknown analyte samples.

\section{Ion-pair Method Using BTB}

Suitable aliquots of the stock solution of TEL, PRO, $\mathrm{CRV}$ and BIS in the concentration range shown in (Table 1) were transferred into a series of $25 \mathrm{ml}$ separated funnels. Then, $2.0 \mathrm{ml}$ of the buffer solution of $\mathrm{pH}=2$ for TEL or CRV and $\mathrm{pH} 4$ for PRO or BIS were added in each case and the volume was completed to $10 \mathrm{ml}$ with distilled water. The contents were extracted with $10 \mathrm{ml}$ dichloromethane and the organic layer was dried over anhydrous sodium sulfate. The absorbance of each solution was measured at $402 \mathrm{~nm}$ against a reagent blank after 5 min. A linear equation for each standard curve was calculated by linear regression.

\section{Procedure for Tablets}

Ten tablets of each commercial pharmaceutical formulation for TEL, PRO, CRV and BIS were crushed, powdered, weighed out and the average weight of one tablet was determined. An accurate weight equivalent to $10 \mathrm{mg}$ each drug and 
then active component was transferred into a $100 \mathrm{ml}$ measuring flask. About $25 \mathrm{ml}$ of distilled water was added and the mixture was shaken thoroughly for about $5 \mathrm{~min}$. Then, it was diluted up to the mark with distilled water, mixed well and filtered using filter paper. An aliquot of this solution was diluted appropriately to obtain the working concentrations and analyzed as described under the standard procedure.

\section{Procedures for Human Serum and Urine}

The proposed methods were applied to the determination of the studied drugs in spiked urine and serum provided from several healthy volunteers. Spiked urine was 50 -fold diluted with distilled water. A $10 \mathrm{ml}$ of serum sample was deproteinzed by adding $5 \mathrm{ml}$ of acetonitrile in a centrifuge for $5 \mathrm{~min}$ at $1000 \mathrm{rpm}$. The supernatant was used to investigate recovery. Add an aliquot of standard aqueous solution of each drug to $1.0 \mathrm{ml}$ of diluted urine or serum. Proceed as described above. A blank value was determined by treating drug-free urine and drug -free serum in the same way. The absolute recovery was determined for each drug by comparing the representative absorbance of the treated urine or serum samples with the absorbance of the standard drug at the same concentration.

\section{RESULTS AND DISCISSION}

\section{Absorption Spectra}

According to the experimental methods, the absorption spectra of PRO solution, the reagent solution (mixed solution of BCG and buffer solution), PRO-BCG complex (against dichloromethane) and dichloromethane were obtained in the wavelength range of 200 600 $\mathrm{nm}$ (Fig. 2).

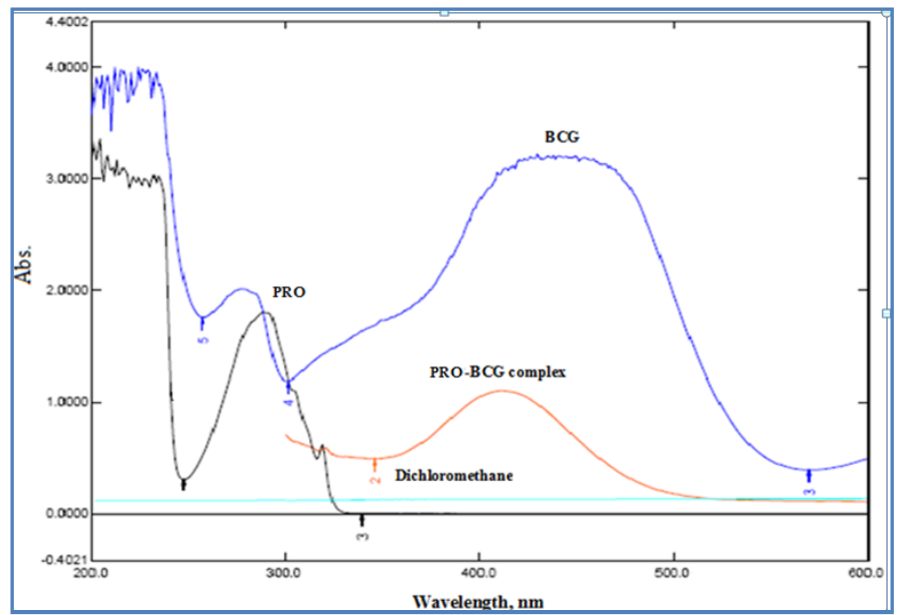

Fig. 2: Absorption spectra of PRO, BCG, PRO-BCG complex and dichloromethane.

The colorless blanks have practically negligible absorbance. The absorption maximum of the reagent solution was at $430 \mathrm{~nm}$. When PRO was added into the reagent solution, BCG reacted with PRO to form ion-pair complex, the color of the solution changed and the maximum absorbance wavelength was $402 \mathrm{~nm}$; compared with the maximum absorbance wavelength of the reagent solution, hypsochromic shift was $28 \mathrm{~nm}$. So $402 \mathrm{~nm}$ were chose as the determination wavelength against dichloromethane.

\section{Optimization of the Reaction Conditions}

A number of preliminary experiments established optimum conditions necessary for rapid and quantitative formation of colored ion-paired complexes to achieve the maximum stability and sensitivity. Optimum condition was fixed by varying one parameter at a time while keeping other parameter constant and observing its effect on the absorbance.

\section{Effect of Buffer Type and pH}

The effect of $\mathrm{pH}$ was studied by extracting the colored complexes in the presence of $\mathrm{KCl}-\mathrm{HCl}$ buffer $(\mathrm{pH} 1.0-2.2)$ and $\mathrm{NaOAc}-\mathrm{HCl}$ (pH 1.99-4.92). It was evident that the maximum color intensity and constant absorbance were observed in $\mathrm{KCl}-\mathrm{HCl}$ buffer of $\mathrm{pH} 2.0$ for TEL or CRV with BCG or BTB and in $\mathrm{NaOAc}-\mathrm{HCl}$ buffer of $\mathrm{pH} 4.0$ for PRO or BIS with BCG or BTB. Buffer volume was determined by applying the same experiment and variation the volume regularly $(0.5-4.0 \mathrm{ml})$. The higher absorbance value obtained at using $2.0 \mathrm{ml}$ of buffer solutions.

\section{Effect of Reagent Concentration}

The effect of the amount of reagents on the intensity of the color development was examined by measuring the absorbance of the solutions containing a fixed concentration of the drugs and varied amounts of the respective reagent. It was found that $2.0 \mathrm{ml}$ of $1.0 \times 10^{-3} \mathrm{M}$ BCG or BTB was sufficient for maximum absorbance. So any excess of reagents has no effect on the determination of the drugs.

\section{Choice of Organic Solvents}

Several organic solvents, such as chloroform, carbon tetrachloride, and ethyl acetate, in addition to dichloromethane were examined for their ability to extract the drug-dye ion-pairs. The latter was found to be the most suitable solvent in terms of extraction efficiency for both methods and considerably lower extraction ability for the reagent blank and shortest time to reach the equilibrium between both phases.

\section{Shaking Time and Stability of the Ion-pair Complexes}

Shaking time ranging from $0.5-4.0 \mathrm{~min}$ was tested to ascertain the extraction of the complex. Maximum and constant absorbance value was obtained when extracted after $2.0 \mathrm{~min}$ shaking. The stability of the ion-pair complexes formed between the studied drugs and BCG or BTB was evaluated. Although the ion-pairs were obtained instantaneously, constant absorbance readings were obtained after not less than $5.0 \mathrm{~min}$ of standing at room temperature $\left(25 \pm 2{ }^{\circ} \mathrm{C}\right)$. Ion-pairs were stable for at least $24 \mathrm{~h}$ without any change in color intensity or in $\lambda_{\max }$.

\section{Composition of Ion-pair Complexes}

Anionic dyes such as BCG or BTB forms ion-pair complex with the positively charged drugs. The drug-dye 
stoichiometric ratios were established by Job's method of continuous variation (Job, 1928). In this method, $1.0 \times 10^{-3} \mathrm{M}$ solutions of drugs and reagents were mixed in varying volume ratios in such a way that the total volume of each mixture was the same.

The absorbance of each solution was measured and plotted against the mole fraction of the drug (Fig. 3). This procedure showed the formation of 1: 1 ion-pair. The suggested reaction pathway for the reaction product of PRO-BCG ion-pair complex formation for example, is given in Fig. 4. These complexes were probably formed via electrostatic interaction between the most basic center in the drug molecule (amino group) and the sulphonic acid group of the dye.
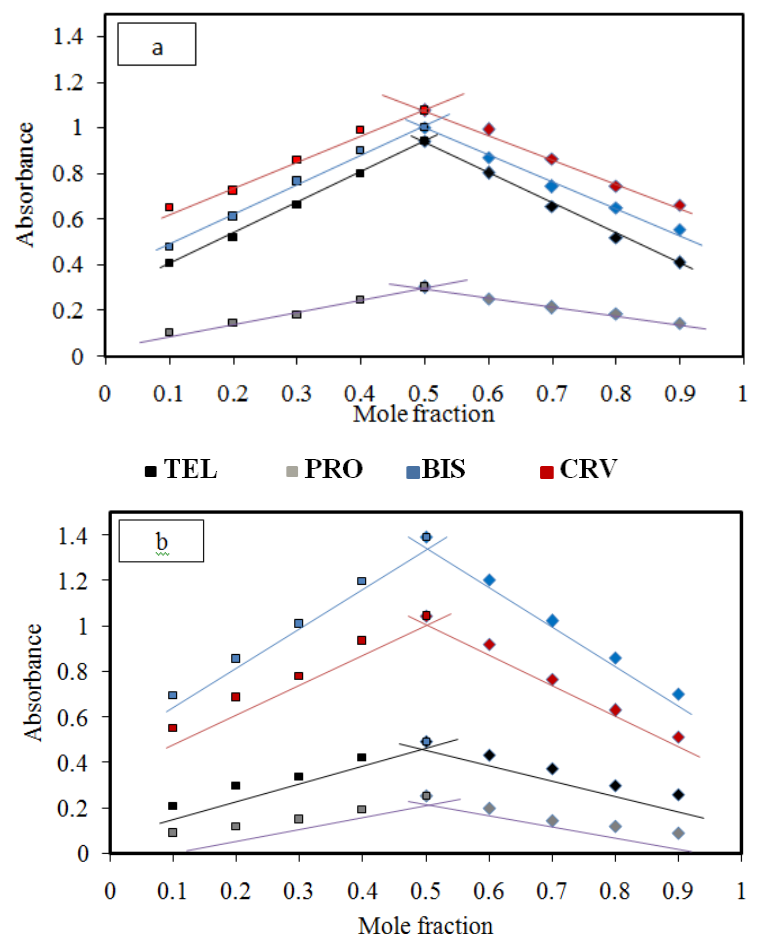

Fig. 3: Continuous variations method applied for (a) BCG and (b) BTB with each drugs.
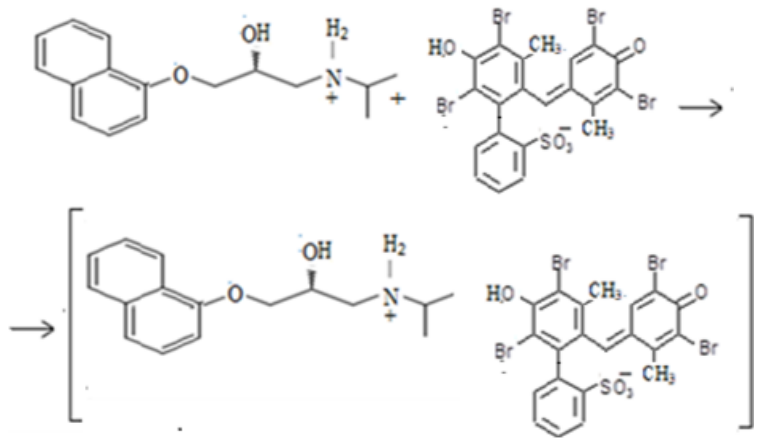

Fig. 4: Suggested mechanism of PRO-BCG ion-pair complex formation.

\section{Calibration Curves}

Under the described experimental conditions, calibration curves for proposed methods were constructed (Fig. 5). The regression parameters given in the regression equation calculated from the calibration graphs along with the standard deviations of the slope $\left(S_{b}\right)$ and the intercept $\left(S_{a}\right)$ are also given in Table 1 . The linearity of calibration graphs was proved by the high values of the correlation coefficient ( $r$ ) and the small values of the $y$-intercepts of the regression equations. The apparent molar absorptivity, Sandell sensitivity, limits of detection and quantification of all the methods were also calculated (Miller and Miller, 2005) and recorded in Table 1. Only it could be concluded that best sensitivity was achieved with BCG.
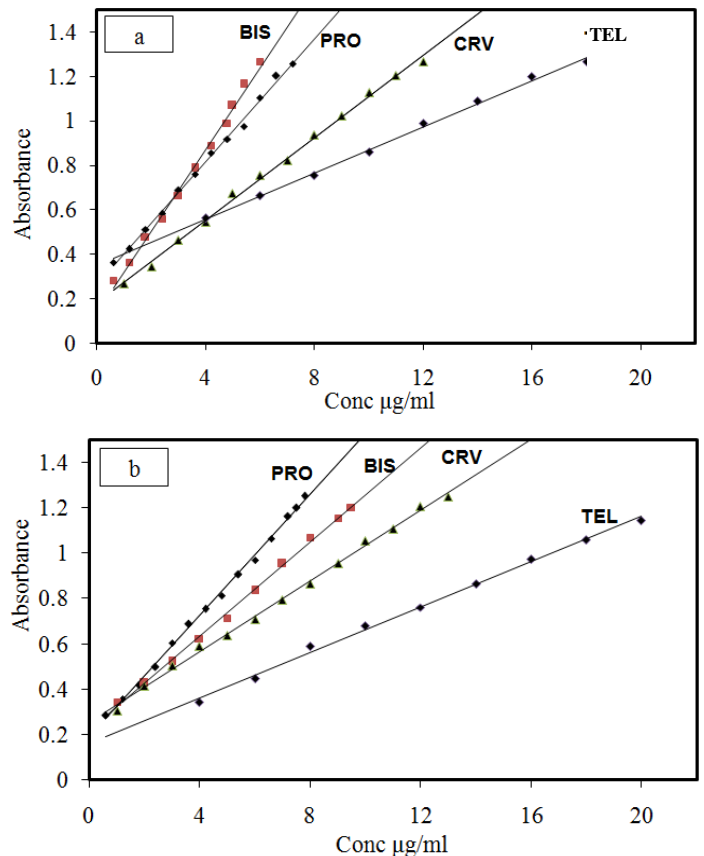

Fig. 5: Calibration curves of ion-pair complexes with: (a) BCG and (b) BTB.

\section{Accuracy and Precision}

In order to determine the accuracy and precision of the proposed methods, pure drug solutions at three different concentration levels (within the working range) were prepared and analyzed in seven replicates during the same day (intra-day precision) and on five consecutive days (inter-day precision) and the results are presented in Table 2, 3 .

Precision and accuracy were based on the calculated relative standard deviation ( $\mathrm{RSD}, \%)$ and relative error (RE, \%) of the found concentration compared to the theoretical one, respectively and indicate that the proposed method is highly accurate and reproducible repeatability and usefulness of the proposed methods in the routine analysis.

\section{Analysis of Dosage Forms}

To evaluate the validity and reproducibility of the methods, known amounts of the studied drugs were added to the previously analyzed pharmaceutical preparations and the mixtures were analyzed by the proposed methods. The percent recoveries are given in Table 4. Interference studies revealed that the common excipients and other additives such as lactose, starch, gelatin, talc and magnesium trisilicate, that are usually present in the tablet dosage forms did not interfere at their regularly added levels. 
Table 1: Analytical parameters and optical characteristics for the studied drugs with BCG and BTB.

\begin{tabular}{|c|c|c|c|c|c|c|c|c|}
\hline \multirow[t]{2}{*}{ Parameters } & \multicolumn{4}{|c|}{ BTB } & \multicolumn{4}{|c|}{ BCG } \\
\hline & TEL & PRO & CRV & BIS & TEL & PRO & CRV & BIS \\
\hline$\overline{\mathrm{pH}}$ & 2 & 4 & 2 & 4 & 2 & 4 & 2 & 4 \\
\hline Beer's law limit, $\mu \mathrm{g} / \mathrm{ml}$ & $4.0-16$ & $0.6-6.6$ & $1.0-11$ & $0.6-6.6$ & $4.0-20$ & $0.6-7.8$ & $1.0-12$ & $1.0-9$ \\
\hline Molar absorptivity, $1 \mathrm{~mol}^{-1} \mathrm{~cm}^{-1}$ & $3.96 \times 10^{4}$ & $2.75 \times 10^{4}$ & $5.86 \times 10^{4}$ & $6.66 \times 10^{4}$ & $3.01 \times 10^{4}$ & $2.41 \times 10^{4}$ & $5.02 \times 10^{4}$ & $6.58 \times 10^{4}$ \\
\hline Sandell's sensitivity, $\mathrm{ng} / \mathrm{cm}^{2}$ & 12.97 & 5.0 & 6.9 & 4.8 & 17.06 & 5.7 & 8.08 & 4.9 \\
\hline Correlation coefficient & 0.9972 & 0.9995 & 0.9999 & 0.9955 & 0.9991 & 0.9992 & 0.9978 & 0.9966 \\
\hline $\mathrm{LOD}, \mu \mathrm{g} / \mathrm{ml}$ & 0.8000 & 0.2529 & 0.4980 & 0.3056 & 0.9920 & 0.3773 & 0.6675 & 0.4269 \\
\hline $\mathrm{LOQ}, \mu \mathrm{g} / \mathrm{ml}$ & 2.6640 & 0.8421 & 1.6583 & 1.0177 & 3.3035 & 1.2566 & 2.2229 & 1.4218 \\
\hline Linear regression equation & $\mathrm{Y}=\mathrm{a}+\mathrm{bX}, \mathrm{v}$ & $\mathrm{eY}$ is the $\mathrm{ab}$ & ance, $a$ is th & ercept, b is tl & ope and $\mathrm{X}$ is & e concentratic & $\mathrm{n} \mu \mathrm{g} / \mathrm{ml}$ & \\
\hline Intercept (a) & 0.1788 & 0.0654 & 0.1432 & 0.2085 & 0.1504 & 0.1980 & 0.2714 & 0.1310 \\
\hline Slope (b) & 0.0625 & 0.1977 & 0.1004 & 0.1636 & 0.0504 & 0.1325 & 0.0749 & 0.1171 \\
\hline $\mathrm{S}_{\mathrm{y} / \mathrm{x}}$ & $10.14 \times 10^{-3}$ & $67.48 \times 10^{-3}$ & $4.90 \times 10^{-3}$ & $57.73 \times 10^{-3}$ & $14.14 \times 10^{-3}$ & $39.58 \times 10^{-3}$ & $8.03 \times 10^{-3}$ & $25.82 \times 10^{-3}$ \\
\hline S.D. of slope $\left(S_{b}\right)$ & $13.17 \times 10^{-4}$ & $60.56 \times 10^{-3}$ & $8.55 \times 10^{-4}$ & $16.13 \times 10^{-3}$ & $12.7 \times 10^{-4}$ & $6.55 \times 10^{-3}$ & $3.54 \times 10^{-2}$ & $5.4 \times 10^{-3}$ \\
\hline S.D. of intercept $\left(S_{3}\right)$ & $24.75 \times 10^{-3}$ & $45.49 \times 10^{-4}$ & $11.9 \times 10^{-3}$ & $10.64 \times 10^{-4}$ & $39.59 \times 10^{-3}$ & $58.06 \times 10^{-3}$ & $13.46 \times 10^{-2}$ & $58.03 \times 10^{-3}$ \\
\hline
\end{tabular}

Table 2: Evaluation of intra-day accuracy and precision for the studied drugs with BCG and BTB.

\begin{tabular}{|c|c|c|c|c|c|c|}
\hline Method & drug & Drug taken, $\mu \mathrm{g} / \mathrm{ml}$ & Drug found, $\mu \mathrm{g} / \mathrm{ml}$ & Recovery $^{a}, \%$ & $\mathbf{R S D}^{\mathbf{b}}, \%$ & $\mathbf{R E}^{\mathrm{c}}, \%$ \\
\hline \multirow{12}{*}{ BCG } & \multirow{3}{*}{ TEL } & 6 & 5.99 & 99.999 & 0.993 & -0.001 \\
\hline & & 10 & 9.99 & 99.996 & 1.826 & -0.004 \\
\hline & & 16 & 16.01 & 100.062 & 0.480 & 0.062 \\
\hline & \multirow{3}{*}{ PRO } & 2.4 & 2.39 & 99.999 & 1.459 & -0.001 \\
\hline & & 4.2 & 4.19 & 99.998 & 1.316 & -0.002 \\
\hline & & 5.4 & 5.39 & 99.997 & 0.937 & -0.185 \\
\hline & \multirow{3}{*}{ CRV } & 4 & 3.99 & 99.999 & 1.848 & -0.001 \\
\hline & & 7 & 6.99 & 99.998 & 0.875 & -0.002 \\
\hline & & 10 & 9.99 & 99.996 & 0.419 & -0.004 \\
\hline & \multirow{3}{*}{ BIS } & 3.0 & 2.99 & 99.996 & 0.800 & -0.333 \\
\hline & & 4.2 & 4.19 & 99.876 & 1.093 & -0.238 \\
\hline & & 6.0 & 5.99 & 99.999 & 0.302 & -0.166 \\
\hline \multirow{12}{*}{ ВТВ } & \multirow{3}{*}{ TEL } & 8 & 7.99 & 99.999 & 1.805 & -0.001 \\
\hline & & 12 & 11.99 & 99.999 & 0.812 & -0.001 \\
\hline & & 16 & 15.99 & 99.993 & 0.804 & -0.007 \\
\hline & \multirow{3}{*}{ PRO } & 3.6 & 3.59 & 99.999 & 0.657 & -0.001 \\
\hline & & 5.4 & 5.39 & 99.999 & 0.655 & -0.001 \\
\hline & & 6.6 & 6.59 & 99.999 & 0.823 & -0.001 \\
\hline & \multirow{3}{*}{ CRV } & 4 & 4.00 & 100.000 & 1.142 & 0.000 \\
\hline & & 8 & 7.99 & 99.999 & 1.159 & -0.001 \\
\hline & & 11 & 10.99 & 99.999 & 0.827 & -0.001 \\
\hline & \multirow{3}{*}{ BIS } & 3.0 & 2.99 & 99.996 & 1.278 & -0.333 \\
\hline & & 5.0 & 4.99 & 99.997 & 1.177 & -0.200 \\
\hline & & 7.0 & 6.99 & 99.999 & 0.538 & -0.142 \\
\hline
\end{tabular}

${ }^{a}$ Mean value of five determinations; ${ }^{b}$ Relative standard deviation (\%); ${ }^{c}$ Relative error (\%).

Table 3: Evaluation of inter-day accuracy and precision for the studied drugs with BCG and BTB.

\begin{tabular}{|c|c|c|c|c|c|c|}
\hline Method & drug & Drug taken $\mu \mathrm{g} / \mathrm{ml}$ & Drug found, $\mu \mathrm{g} / \mathrm{ml}$ & Recovery $^{\mathrm{a}}, \%$ & $\mathbf{R S D}^{\mathbf{b}}, \%$ & $\mathbf{R E}^{\mathrm{c}}, \%$ \\
\hline \multirow{12}{*}{ BCG } & \multirow{3}{*}{ TEL } & 6 & 5.99 & 99.999 & 1.580 & -0.001 \\
\hline & & 10 & 9.99 & 99.999 & 1.415 & -0.001 \\
\hline & & 16 & 16.02 & 100.150 & 0.389 & 0.150 \\
\hline & \multirow{3}{*}{ PRO } & 2.4 & 2.39 & 99.995 & 1.320 & -0.005 \\
\hline & & 4.2 & 4.19 & 99.996 & 1.158 & -0.004 \\
\hline & & 5.4 & 5.39 & 99.998 & 0.356 & -0.002 \\
\hline & \multirow{3}{*}{ CRV } & 4 & 3.99 & 99.999 & 1.141 & -0.001 \\
\hline & & 7 & 6.98 & 99.857 & 0.899 & -0.143 \\
\hline & & 10 & 9.99 & 99.998 & 0.649 & -0.002 \\
\hline & \multirow{3}{*}{ BIS } & 3.0 & 2.99 & 99.796 & 0.892 & -0.333 \\
\hline & & 4.2 & 4.19 & 99.888 & 0.673 & -0.238 \\
\hline & & 6.0 & 5.99 & 99.998 & 0.453 & -0.166 \\
\hline \multirow{12}{*}{ ВТВ } & \multirow{3}{*}{ TEL } & 8 & 7.99 & 99.997 & 0.906 & -0.125 \\
\hline & & 12 & 11.99 & 99.999 & 1.288 & -0.036 \\
\hline & & 16 & 15.99 & 99.998 & 0.558 & -0.002 \\
\hline & \multirow{3}{*}{ PRO } & 3.6 & 3.59 & 99.999 & 0.669 & -0.001 \\
\hline & & 5.4 & 5.39 & 99.999 & 1.050 & -0.001 \\
\hline & & 6.6 & 6.59 & 99.999 & 0.260 & -0.001 \\
\hline & \multirow{3}{*}{ CRV } & 4 & 3.99 & 99.997 & 0.917 & -0.003 \\
\hline & & 8 & 7.99 & 99.999 & 1.036 & -0.001 \\
\hline & & 11 & 10.99 & 99.999 & 0.488 & -0.001 \\
\hline & \multirow{3}{*}{ BIS } & 3.0 & 2.99 & 99.999 & 1.845 & -0.333 \\
\hline & & 5.0 & 4.99 & 99.989 & 0.742 & -0.200 \\
\hline & & 7.0 & 6.99 & 99.998 & 0.804 & -0.142 \\
\hline
\end{tabular}

${ }^{\mathrm{a}}$ Mean value of five determinations; ${ }^{\mathrm{b}}$ Relative standard deviation (\%); ${ }^{\mathrm{c}}$ Relative error (\%). 
Table 4: Recovery of the studied drugs in pharmaceutical formulations with BCG and BTB.

\begin{tabular}{|c|c|c|c|c|c|c|c|}
\hline Method & Drug & Drugformulation & Drug taken $\mu \mathrm{g} / \mathrm{ml}$ & Drug found, $\mu \mathrm{g} / \mathrm{ml}$ & Recovery $^{\mathrm{a}}, \%$ & $\mathbf{R S D}^{\mathbf{b}}, \%$ & $\mathbf{R E}^{\mathrm{c}}, \%$ \\
\hline \multirow{12}{*}{$\mathrm{BCG}$} & \multirow{3}{*}{ TEL } & \multirow{3}{*}{ Micardis $40 \mathrm{mg} /$ tablet } & 6 & 5.99 & 99.996 & 2.458 & -0.004 \\
\hline & & & 10 & 9.99 & 99.999 & 1.685 & -0.001 \\
\hline & & & 16 & 15.99 & 99.997 & 1.429 & -0.003 \\
\hline & \multirow{3}{*}{ PRO } & \multirow{3}{*}{ Inderal $40 \mathrm{mg} /$ tablet } & 2.4 & 2.39 & 99.999 & 1.446 & -0.001 \\
\hline & & & 4.2 & 4.19 & 99.999 & 2.140 & -0.001 \\
\hline & & & 5.4 & 5.39 & 99.998 & 1.748 & -0.002 \\
\hline & \multirow{3}{*}{ CRV } & \multirow{3}{*}{ Carvid $7.5 \mathrm{mg} /$ tablet } & 4 & 3.99 & 99.994 & 1.492 & -0.006 \\
\hline & & & 7 & 6.99 & 99.998 & 1.881 & -0.002 \\
\hline & & & 10 & 9.99 & 99.966 & 0.627 & -0.004 \\
\hline & \multirow{3}{*}{ BIS } & \multirow{3}{*}{ Concor $10 \mathrm{mg} /$ tablet } & 3.0 & 2.99 & 99.996 & 1.889 & -0.004 \\
\hline & & & 4.2 & 4.19 & 99.990 & 0.901 & -0.010 \\
\hline & & & 6.0 & 5.99 & 99.998 & 1.345 & -0.002 \\
\hline \multirow{12}{*}{ ВТВ } & \multirow{3}{*}{ TEL } & \multirow{3}{*}{ Micardis $40 \mathrm{mg} /$ tablet } & 8 & 7.99 & 99.999 & 2.530 & -0.001 \\
\hline & & & 12 & 11.99 & 99.996 & 2.592 & -0.004 \\
\hline & & & 16 & 15.99 & 99.999 & 2.425 & -0.001 \\
\hline & \multirow{3}{*}{ PRO } & \multirow{3}{*}{ Inderal $40 \mathrm{mg} /$ tablet } & 3.6 & 3.59 & 99.996 & 1.035 & -0.004 \\
\hline & & & 5.4 & 5.39 & 99.852 & 1.843 & -0.148 \\
\hline & & & 6.6 & 6.59 & 99.999 & 1.736 & -0.001 \\
\hline & \multirow{3}{*}{ CRV } & \multirow{3}{*}{ Carvid $7.5 \mathrm{mg} /$ tablet } & 4 & 3.99 & 99.999 & 1.723 & -0.001 \\
\hline & & & 8 & 7.99 & 99.997 & 1.327 & -0.003 \\
\hline & & & 11 & 10.99 & 99.999 & 0.819 & -0.001 \\
\hline & \multirow{3}{*}{ BIS } & \multirow{3}{*}{ Concor $10 \mathrm{mg} /$ tablet } & 3.0 & 2.99 & 99.999 & 1.767 & -0.001 \\
\hline & & & 5.0 & 4.99 & 99.998 & 1.767 & -0.002 \\
\hline & & & 7.0 & 6.99 & 99.999 & 1.121 & -0.001 \\
\hline
\end{tabular}

${ }^{\mathrm{a}}$ Mean value of five determinations; ${ }^{b}$ Relative standard deviation (\%); ${ }^{\mathrm{c}}$ Relative error (\%).

Table 5: Recovery of the studied drugs in human serum with BCG and BTB.

\begin{tabular}{|c|c|c|c|c|c|c|}
\hline Method & Drug & Drug taken $\mu \mathrm{g} / \mathrm{ml}$ & Drug found, $\mu \mathrm{g} / \mathrm{ml}$ & Recovery $^{\mathbf{a}}$, \% & RSD $^{b}, \%$ & $\mathbf{R E}^{\mathbf{c}}, \%$ \\
\hline \multirow{12}{*}{ BCG } & \multirow{3}{*}{ TEL } & 6 & 5.99 & 99.899 & 0.937 & -0.101 \\
\hline & & 10 & 9.99 & 99.996 & 0.911 & -0.004 \\
\hline & & 16 & 15.99 & 99.997 & 0.448 & -0.003 \\
\hline & \multirow{3}{*}{ PRO } & 2.4 & 2.39 & 99.995 & 3.541 & -0.005 \\
\hline & & 4.2 & 4.18 & 99.666 & 1.914 & -0.334 \\
\hline & & 5.4 & 5.40 & 100.005 & 2.461 & 0.005 \\
\hline & \multirow{3}{*}{ CRV } & 4 & 3.99 & 99.998 & 2.465 & -0.002 \\
\hline & & 7 & 6.99 & 99.962 & 0.876 & -0.038 \\
\hline & & 10 & 9.99 & 99.998 & 1.294 & -0.002 \\
\hline & \multirow{3}{*}{ BIS } & 3 & 2.99 & 99.996 & 2.14 & -0.004 \\
\hline & & 4.2 & 4.19 & 99.965 & 1.722 & -0.035 \\
\hline & & 6 & 5.99 & 99.960 & 1.370 & -0.040 \\
\hline \multirow{12}{*}{ ВТВ } & \multirow{3}{*}{ TEL } & 8 & 7.99 & 99.984 & 2.944 & -0.016 \\
\hline & & 12 & 11.99 & 99.996 & 1.116 & -0.004 \\
\hline & & 16 & 15.99 & 99.991 & 0.613 & -0.009 \\
\hline & \multirow{3}{*}{ PRO } & 3.6 & 3.59 & 99.800 & 1.879 & -0.200 \\
\hline & & 5.4 & 5.39 & 99.999 & 1.146 & -0.001 \\
\hline & & 6.6 & 6.59 & 99.889 & 2.613 & -0.111 \\
\hline & \multirow{3}{*}{ CRV } & 4 & 3.99 & 99.755 & 3.560 & -0.245 \\
\hline & & 8 & 7.99 & 99.966 & 1.787 & -0.034 \\
\hline & & 11 & 11.00 & 100.004 & 1.549 & 0.004 \\
\hline & \multirow{3}{*}{ BIS } & 3 & 2.99 & 99.986 & 1.147 & -0.014 \\
\hline & & 5 & 4.96 & 99.306 & 1.375 & -0.694 \\
\hline & & 7 & 6.99 & 99.999 & 2.321 & -0.001 \\
\hline
\end{tabular}

${ }^{a}$ Mean value of five determinations; ${ }^{b}$ Relative standard deviation (\%); ${ }^{c}$ Relative error (\%). 
Table 6: Recovery of the studied drugs in urine with BCG and BTB.

\begin{tabular}{|c|c|c|c|c|c|c|}
\hline Method & Drug & $\begin{array}{l}\text { Drug taken } \\
\mu \mathrm{g} / \mathrm{ml}\end{array}$ & $\begin{array}{l}\text { Drug found, } \\
\mu \mathrm{g} / \mathrm{ml}\end{array}$ & $\begin{array}{l}\operatorname{Recovery}^{\mathrm{a}}, \\
\%\end{array}$ & $\begin{array}{l}\mathbf{R S D}^{\mathrm{b}}, \\
\%\end{array}$ & $\begin{array}{l}\mathbf{R} \mathbf{E}^{\mathbf{c}}, \\
\%\end{array}$ \\
\hline \multirow{11}{*}{ BCG } & \multirow{3}{*}{ TEL } & 6 & 5.99 & 99.933 & 2.966 & -0.067 \\
\hline & & 10 & 9.99 & 99.999 & 2.413 & -0.001 \\
\hline & & 16 & 15.99 & 99.977 & 1.972 & -0.023 \\
\hline & \multirow{3}{*}{ PRO } & 2.4 & 2.39 & 99.999 & 2.144 & -0.001 \\
\hline & & 4.2 & 4.19 & 99.800 & 1.799 & -0.200 \\
\hline & & 5.4 & 5.39 & 99.999 & 1.363 & -0.001 \\
\hline & \multirow{4}{*}{ CRV } & 4 & 4.00 & 100.141 & 2.165 & 0.141 \\
\hline & & 7 & 6.99 & 99.999 & 1.151 & -0.001 \\
\hline & & 10 & 9.99 & 99.966 & 0.764 & -0.004 \\
\hline & & 3.0 & 2.99 & 99.996 & 1.549 & -0.004 \\
\hline & \multirow[t]{3}{*}{ BIS } & 4.2 & 4.19 & 99.999 & 1.152 & -0.001 \\
\hline \multirow{13}{*}{ ВТВ } & & 6.0 & 5.99 & 99.999 & 1.896 & -0.001 \\
\hline & & 8 & 8.00 & 100.034 & 1.280 & -0.034 \\
\hline & \multirow[t]{3}{*}{ TEL } & 12 & 11.98 & 99.916 & 0.991 & -0.084 \\
\hline & & 16 & 15.99 & 99.997 & 2.093 & -0.003 \\
\hline & & 3.6 & 3.60 & 100.055 & 1.951 & 0.055 \\
\hline & \multirow[t]{3}{*}{ PRO } & 5.4 & 5.39 & 99.999 & 1.508 & -0.001 \\
\hline & & 6.6 & 6.59 & 99.998 & 1.038 & -0.002 \\
\hline & & 4 & 3.99 & 99.961 & 1.881 & -0.039 \\
\hline & \multirow[t]{3}{*}{ CRV } & 8 & 7.99 & 99.875 & 2.067 & -0.125 \\
\hline & & 11 & 10.99 & 99.999 & 0.547 & -0.001 \\
\hline & & 3.0 & 2.99 & 99.999 & 1.388 & -0.001 \\
\hline & \multirow[t]{2}{*}{ BIS } & 5.0 & 4.99 & 99.998 & 2.523 & -0.002 \\
\hline & & 7.0 & 6.99 & 99.965 & 1.501 & -0.035 \\
\hline
\end{tabular}

\section{Analysis of Biological Fluids}

The high sensitivity of the proposed methods, also allowed the in vitro determination of TEL, PRO, CRV and BIS in spiked human serum and urine samples. Thus the proposed methods are sufficient for routine estimation of the drugs in human serum and urine. The results obtained are satisfactorily accurate and precise (Tables 5, 6).

\section{CONCLUSION}

The proposed methods are simple, sensitive, accurate, and time saving, thereby encouraging their application in the analysis and quality control of these drugs in their pharmaceutical preparations and biological fluids. Statistical analysis proves that the methods are reproducible and selective for the routine analysis of the said drugs. The performance order of the proposed methods is BCG-drugs more sensitive than BTB-drugs.

\section{REFERENCES}

Abdel-Hamid ME. Comparative LC-MS and HPLC analyses of selected antiepileptics and beta-blocking drugsIL Farmaco, 2000,55, 136140 .

Alarfaj NA. Square_Wave adsorptive stripping voltammetric determination of antihypertensive agent telmisartan in tablets and its application to human plasma. J Anal Chem, 2013; 68:335-340.

Anderson P, Knoben J, Troutman W. Handbook of clinical drug data. McGraw-Hill, New York. 10 ${ }^{\text {th }}$ edition, 2002, pp 354-355.

Babu RV, Inamadugu JK, Pilli NR, Sreenivasulu V, Ponneri V. Simultaneous determination of telmisartan and amlodipine in human plasma by LC-MS/MS and its application in a human pharmacokinetic study. J Pharm Anal, 2012; 5:319-326.

Basavaiah K, Chandrashekar U, Prameela HC, Nagegowda P. Titrimetric and spcetrometric determination of propranolol hydrochloride using chloramine-T. Indian Drugs, 2004; 41:303-305.
Belal TS, Shaalan RA, El Yazbi FA, Elonsy SM. Validated stability-Indicating HPLC-DAD determination of the antihypertensive binary mixture of carvedilol and hydrochlorothiazide in tablet dosage forms. Chromatographia, 2013; 76: 1707-1720.

Cardoso SG, Ieqqli CV, Pomblum SC. Spectrophotometric determination of carvedilol in pharmaceutical formulations through charge-transfer and ion-pair complexation reactions. Die Pharmazie, 2007; 62:34-37.

Caudron E, Laurent S, Billaud EM, Prognon P. Simultaneous determination of the acid/base antihypertensive drugs celiprolol, bisoprolol and irbesartan in human plasma by liquid chromatography. J Chromatogr B, 2004; 801:339-345.

Ding L, Zhou X, Guo X, Song Q, He J, Xu G. LC-ESI-MS method for the determination of bisoprolol in human plasma. J Pharm Biomed Anal, 2007; 44: 520-525.

Dogan B, Ozkan SA. Electrochemical behavior of carvedilol and its adsorptive stripping determination in dosage forms and biological fluids. Electroanal, 2005; 17:2074-2083.

Dubach P, Myers J, Bonetti P, Schertler T, Froelicher V, Wagner D. Effects of bisoprolol fumarate on left ventricular size, function, and exercise capacity in patients with heart failure: Analysis with magnetic resonance myocardial tagging. Am Heart J, 2002; 143:676-683.

El-Didamony AM, Saad MZ, Ramadan GM. Kinetic spectrophotometric determination of $\beta$-adrenergic antagonists using alkaline potassium permanganate. Main Group Chem, 2012; 11:245-258.

El-Didamony AM, Shehatab AM. Spectrophotometric determination of $\beta$-adrenergic antagonists drugs via ion-pair complex formation using MO and EBT. Opt Spectrosc, 2014; 117:492499.

El-Didamony AM. A sensitive spectrophotometric method for the determination of propranolol $\mathrm{HCl}$ based on oxidation bromination reactions. Drug Test Anal, 2010; 2:122-129.

El-Sahart YS. Simultaneous high performance liquid chromatographic assay of frusemide and propranolol $\mathrm{HCl}$ and its application in a pharmacokinetic study. J Pharm Biomed Anal, 2003; 33:699-709.

Flanagan RJ. Guidelines for the interpretation of analytical toxicology results and unit of measurement conversion factors. Ann Clin Biochem, 1998; 35:261-265. 
Goyal RN, Tyagi A, Bachheti N, Bishnoi S. Voltammetric determination of bisoprolol fumarate in pharmaceutical formulations and urine using single-wall carbon nanotubes modified glassy carbon electrode. Electrochim Acta, 2008; 53: 2802-2808.

Guptaa VK, Jain R, Lukram O, Agarwal S, Dwivedi A. Simultaneous determination of ramipril, ramiprilat and telmisartan in human plasma using liquid chromatography-tandem mass spectrometry. Talanta, 2011; 83:709-716.

Ilango K, Kumar PSS. Validated spectrophotometric methods for the simultaneous determination of telmisartan and atorvastatin in bulk and tablets. Pharm Methods, 2012; 3:112-116.

Job P. Formation and stability of inorganic complexes in solution. Annali di Chim, 1928; 9:113-203.

Joshi SJ, Karbhari PA, Bhoir SI, Bindu KS, Das C. RP-HPLC method for simultaneous estimation of bisoprolol fumarate and hydrochlorothiazide in tablet formulation. J Pharm Biomed Anal, 2010; 52:362-371.

Jyothi AA, Nalluri BN. Development and validation of rapid HPLC - PDA method for the simultaneous estimation of rosuvastatin calcium and telmisartan in bulk and dosage forms. J Pharm Res, 2012; 5:3994-3997.

Machida M, Watanabe M, Takechi S, Kakinoki S, Nomura A. Measurement of carvedilol in plasma by high-performance liquid chromatography with electrochemical detection. J Chromatogr B, 2003; 798:187-191.

Miller JN, Miller JC. Statistics and chemometrics for analytical chemistry. 5th edn. Prentice Hall, England, 2005, pp 256.

Moffat AC, Osselton MD, Widdop B. Clarke'sanalysis of drugs and poisons in pharmaceuticals, body fluids and postmortem material. Pharmaceutical Press, London. $3^{\text {rd }}$ edition, 2004, pp 760-761.

Önal A. Spectrophotometric and spectrofluorimetric determination of some drugs containing secondary amino group in bulk drug and dosage forms via derivatization with 7-chloro-4nitrobenzofurazon. Quim Nova, 2011; 34:677-682.

Patel LJ, Suhagia BN, Shah PB, Shah RR. Simultaneous estimation of bisoprolol fumarate and hydrochlorothiazide in tablet dosage form by RP-HPLC method. Indian J Pharm Sci, 2006; 68:635-638.

Peste G, Oniscu C, Vlase A. Experimental research for determination of bisoprolol fumarate in human plasma samples using liquid chromatography- tandem mass spectrometry (LC-MS/MS) technique. Rom Biotechnol Lett, 2010; 15: 5140-5145.

Pitt B, Konstam MA. Overview of angiotensin II-receptor antagonists. Am J Cardiol, 1998; 82:47S-49S.

Qin Z, Niu W, Tan R. Spectrophotometric method for the determination of telmisartan with congo red. J Anal Chem, 2009; 64:449454.

Rao RN, Prasad KG, Naidu CG, Maurya PK. Development of a validated liquid chromatographic method for determination of related substances of telmisartan in bulk drugs and formulations. J Pharm Biomed Anal, 2011; 56:471-478.

Rekhi GS, Jambhekar SS, Souney PF, Williams DA. A fluorometric liquid chromatographic method for the determination of propranolol in human serum/plasma. J Pharm Biomed Anal, 1995; 13:1499-1505
Sahu R, Patel VB. Simultaneous spectrophotometric estimation of hydrochlorothiazide and bisoprolol fumarate in combined dosage forms. Indian J Pharm Sci, 2006; 68:764-767.

Salman SAB, Sulaiman SA, Ismail Z, Gan SH. Quantitative determination of propranolol by ultraviolet HPLC in human plasma. Toxicol Mech Methods, 2010; 20:137-142.

Šatínský D, Havlíková L, Solich P. HPLC column-switching technique for sample preparation and fluorescence determination of propranolol in urine using fused-core columns in both dimensions. Anal Bioanal Chem, 2013; 405:6583-6587.

Seelam RR, Chandiran IS, Divi KR, Jayaveera KN. Development and validation of high-performance liquid chromatographytandem mass spectrometric method for simultaneous quantification of telmisartan in human plasma. Int J Pharm Sci Drug Res, 2010; 3:188-192.

Shaikh S, Thusleem OA, Muneera MS, Akmal J, Kondaguli AV, Ruckmani K. A simple and rapid high-performance liquid chromatographic method for the determination of bisoprolol fumarate and hydrochlorothiazide in a tablet dosage form. J Pharm Biomed Anal, 2008; 48:1055-1057.

Sweetman SC, Martindale: The complete drug reference. London: Pharmaceutical Press. 33rd ed, 2002, pp 962-963.

Tutunji MF, Ibrahim HM, Khabbas MH, Tutunji LF. Simultaneous determination of bisoprolol and hydrochlorothiazide in human plasma by HPLC coupled with tandem mass spectrometry. J Chromatogr B, 2009; 877:1689-1697.

Yusuf S, Teo KK, Pogue J, Dyal L, Copland I. Telmisartan, ramipril, or both in patients at high risk for vascular events. N Engl J Med, 2008; 358:1547-1559.

Zahálka L, Matysová L, Śklubalová Z, Klovrzová S, Solich P. Simultaneous determination of propranolol hydrochloride and sodium benzoate in oral liquid preparations by HPLC. Chromatographia, 2013; 76:1553-1558.

Zarghi A, Foroutan SM, Shafaati A, Khoddam A. Quantification of carvedilol in human plasma by liquid chromatography using fluorescence detection: application in pharmacokinetic studies. J Pharm Biomed Anal, 2007; 44:250-253.

Zhang $\mathrm{H}$, Jiang Y, Wen J, Zhou T, Fan G, Wu Y. Rapid determination of telmisartan in human plasma by HPLC using a monolithic column with fluorescence detection and its application to a bioequivalence study. J Chromatogr B, 2009; 877:3729-3733.

\section{How to cite this article:}

Akram M. El-Didamony, Sameh M. Hafeez, Ahmed A. Saad. Application of Bromocresol Green and Bromothymol Blue for the Extractive Spectrophotometric Determination of Anti-hypertensive Drugs. J App Pharm Sci, 2015; 5 (07): 122-129. 